STRUCTURAL BIOLOGY

ISSN 2059-7983

Keywords: FMN-dependent monooxygenase; protein structure; industrial biocatalysis; corrigendum

\section{The oxygenating constituent of 3,6-diketocamphane monooxygenase from the CAM plasmid of Pseudomonas putida: the first crystal structure of a type II Baeyer-Villiger monooxygenase. Corrigendum}

\author{
Michail N. Isupov, ${ }^{a}$ Ewald Schröder, ${ }^{a}$ Robert P. Gibson, ${ }^{a}$ Jean Beecher, ${ }^{a}$ Giuliana \\ Donadio, ${ }^{a}$ Vahid Saneei, ${ }^{a}$ Stephlina A. Dcunha, ${ }^{a}$ Emma J. McGhie, ${ }^{a}$ Christopher \\ Sayer, ${ }^{a}$ Colin F. Davenport, ${ }^{a}$ Peter C. K. Lau, ${ }^{\text {b }}$ Yoshie Hasegawa, ${ }^{c}$ Hiroaki Iwaki, \\ Maria Kadow, ${ }^{d}$ Kathleen Balke, ${ }^{d}$ Uwe T. Bornscheuer, ${ }^{d}$ Gleb Bourenkov ${ }^{\mathbf{e}}$ and \\ Jennifer A. Littlechild ${ }^{\mathrm{a} *}$
}

\begin{abstract}
a The Henry Wellcome Building for Biocatalysis, Biosciences, College of Life and Environmental Sciences, University of Exeter, Stocker Road, Exeter EX4 4QD, England, ${ }^{\mathbf{B}}$ Biotechnology Research Institute, National Research Council Canada, 6100 Royalmount Avenue, Montreal, QC H4P 2R2, Canada, 'Department of Biotechnology, Faculty of Engineering, Kansai University, Japan, ${ }^{\mathbf{d}}$ Department of Biotechnology and Enzyme Catalysis, Institute of Biochemistry, Greifswald University, Felix-Hausdorff-Strasse 4, 17487 Greifswald, Germany, and ${ }^{\mathbf{e} E u r o p e a n ~ M o l e c u l a r ~ B i o l o g y ~ L a b o r a t o r y ~(E M B L), ~}$ Hamburg Outstation, Notkestrasse 85, 22607 Hamburg, Germany. *Correspondence e-mail: j.a.littlechild@exeter.ac.uk
\end{abstract}

A statement is amended in the article by Isupov et al. [(2015). Acta Cryst. D71, 2344-2353].

In the article by Isupov et al. (2015), the statement in $\$ 3.10$ 'Partial sequencing of the large CAM plasmid has now identified a flavin reductase adjacent to the 3,6-DKMO gene on the CAM plasmid (Littlechild \& Isupov, unpublished data)' is withdrawn. The following statement is added: 'A cognate flavin reductase (Fred) from the genome of Pseudomonas putida (strain PpCam), which provides the required FMNH2 for the 3,6-DKMO activity, has been described by Iwaki et al. (2013). Other non-cognate reductases have been reported which can partially support the DKMO activity but not as efficiently as the cognate Fred'.

\section{References}

Isupov, M. N., Schröder, E., Gibson, R. P., Beecher, J., Donadio, G., Saneei, V., Dcunha, S. A., McGhie, E. J., Sayer, C., Davenport, C. F., Lau, P. C., Hasegawa, Y., Iwaki, H., Kadow, M., Balke, K., Bornscheuer, U. T., Bourenkov, G. \& Littlechild, J. A. (2015). Acta Cryst. D71, 2344-2353.

Iwaki, H., Grosse, S., Bergeron, H., Leisch, H., Morley, K., Hasegawa, Y. \& Lau, P. C. K. (2013). Appl. Environ. Microbiol. 79, 3282-3293.

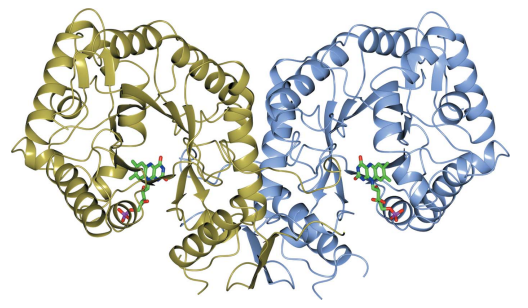

(C) 2018 International Union of Crystallography 